\title{
Associating liver partition and portal vein ligation for staged hepatectomy (ALPPS) - pushing the envelope in modulation of future liver remnant before major hepatectomy
}

\author{
Albert C. Y. Chan ${ }^{1,2}$, Chung Mau Lo ${ }^{1,2}$ \\ ${ }^{1}$ Department of Surgery, Queen Mary Hospital, The University of Hong Kong, Hong Kong, China; ${ }^{2}$ Department of Surgery, The University of \\ Hong Kong-Shenzhen Hospital, Shenzhen 518053, China \\ Correspondence to: Albert C. Y. Chan. Department of Surgery, Queen Mary Hospital, The University of Hong Kong, Hong Kong, China; Department \\ of Surgery, The University of Hong Kong-Shenzhen Hospital, Shenzhen 518053, China. Email: acchan@hku.hk. \\ Comment on: Lang H, de Santibañes E, Schlitt HJ, et al. 10th Anniversary of ALPPS-Lessons Learned and quo Vadis. Ann Surg 2019;269:114-9.
}

Submitted Jul 31, 2019. Accepted for publication Aug 19, 2019.

doi: 10.21037/hbsn.2019.10.28

View this article at: http://dx.doi.org/10.21037/hbsn.2019.10.28

Insufficient future liver remnant (FLR) is an important factor that precludes patient from upfront major liver resection as it predisposes to post-hepatectomy liver failure and mortality. As such, augmentation of FLR by portal vein embolization (PVE) was the conventional approach to improve the safety profile of major hepatectomy. In recent years, associating liver partition and portal vein ligation for staged hepatectomy (ALPPS) has been popularized as an alternative approach for FLR augmentation $(1,2)$. However, the initial inception of the ALPPS procedure was met by criticism for its high incidence of procedurerelated morbidity, such as bile leakage and sepsis (3). In light of this issue, an international registry was set up for collection of cases and experience around the world and soon after that, the first International Expert Meeting was held in Hamburg in 2015 that led to the publication of eight recommendations on terminology of the procedures, indications and techniques for ALPPS (4). Two years later, a pre-congress meeting was held during the EHPBA (European Hepatopancreatobiliary Association) 12 Annual Congress in Mainz, Germany to celebrate the $10^{\text {th }}$ Anniversary of ALPPS (5) since the first case was performed by Prof. Hans Schlitt a decade ago (1). During this meeting, ten different aspects on ALPPS were covered including surgical anatomy, underlying mechanisms, perioperative assessment of liver function, technical approach, indications and its effectiveness in comparison to two-stage hepatectomy.
ALPPS was undoubtedly a complex liver procedure that demands thorough knowledge of the surgical anatomy of the liver vasculatures and biliary system. Preservation of the hepatic artery (HA) in the first stage of ALPPS was mandatory especially for a staged right trisectionectomy to avoid segment 4 ischaemia. A Glissonian approach to control and divide the right HA and bile duct in the second stage was associated with the benefit to avoid inadvertent narrowing of the contralateral biliary pedicle. The hepatic vein drainage should be preserved in stage I. Early transection of the middle hepatic vein (MHV) in stage I could lead to right liver venous outflow problems especially in patients with predominant right anterior section drainage by the MHV.

Concerning the effect of rapid hypertrophy induced by ALPPS, skeptics argued that the future remnant volume gain was merely attributed by tissue odema rather than expansion of hepatocytes. However, recent studies demonstrated the stimulatory effect of ALPPS on cellular proliferation. Not just the liver volume but the future remnant function also improved by the ALPPS procedure (6). Inter-stage hepatic scintigraphy using technetium-99 (Tc99) mebrofenin radioisotope showed that completion stage II hepatectomy could be safely undertaken when the FLR uptake exceeded $2.7 \% / \mathrm{min} / \mathrm{m}^{2}(7)$. With respect to the indications, ALPPS was shown to be safe and feasible in colorectal liver metastases $(8,9)$ and hepatocellular carcinoma $(10,11)$. However, its application for peri- 
hilar cholangiocarcinoma was still controversial as the parenchymal split between the left medial and lateral section would result in many segregated dilated segment 4 bile ducts leading to bile leakage and sepsis (12). Hence, routine application of ALPPS to cholangiocarcinoma could not be recommended at this stage and further studies with different technical approaches are warranted.

In order to reduce the postoperative morbidity and mortality rates after the classical ALPPS procedure, various technical modifications focusing on the parenchymal split have been proposed, e.g., mini-ALPPS, tourniquet ALPPS, ALPPS by radiofrequency ablation or microwave ablation, laparoscopic ALPPS (5). All these technical modifications nonetheless would largely result in a partial split of the liver parenchyma and are designed based on the notion that partial split would achieve the same degree of FLR hypertrophy as a complete split (13). However, there is evidence that a complete split, i.e., classical ALPPS is still more effective to induce a greater degree of FLR hypertrophy without increasing morbidity and mortality rates (14). A complete split in the first stage ALPPS will optimize the chance for FLR hypertrophy and is the only chance to improve the resectability for these patients. Considering the complexity of the procedure and issue of FLR manipulation, the results of ALPPS may be improved if performed by surgeons with experience in living donor liver transplantation including expertise in modulation of portal haemodynamics and management of small-for-size syndrome.

\section{Acknowledgments}

None.

\section{Footnote}

Conflicts of Interest: The authors have no conflicts of interest to declare.

Ethical Statement: The authors are accountable for all aspects of the work in ensuring that questions related to the accuracy or integrity of any part of the work are appropriately investigated and resolved.

\section{References}

1. Schnitzbauer AA, Lang SA, Goessmann H, et al. Right portal vein ligation combined with in situ splitting induces rapid left lateral liver lobe hypertrophy enabling 2 -staged extended right hepatic resection in small-for-size settings. Ann Surg 2012;255:405-14.

2. de Santibanes E, Clavien PA. Playing Play-Doh to prevent postoperative liver failure: the "ALPPS" approach. Ann Surg 2012;255:415-7.

3. Belghiti J, Dokmak S, Schadde E. ALPPS: Innovation for innovation's sake. Surgery 2016;159:1287-8.

4. Oldhafer KJ, Stavrou GA, van Gulik TM, et al. ALPPS-Where Do We Stand, Where Do We Go?: Eight Recommendations From the First International Expert Meeting. Ann Surg 2016;263:839-41.

5. Lang H, de Santibañes E, Schlitt HJ, et al. 10th Anniversary of ALPPS-Lessons Learned and quo Vadis. Ann Surg 2019;269:114-9.

6. Serenari M, Collaud C, Alvarez FA, et al. Interstage Assessment of Remnant Liver Function in ALPPS Using Hepatobiliary Scintigraphy: Prediction of Posthepatectomy Liver Failure and Introduction of the HIBA Index. Ann Surg 2018;267:1141-7.

7. de Graaf W, van Lienden KP, Dinant S, et al. Assessment of future remnant liver function using hepatobiliary scintigraphy in patients undergoing major liver resection. J Gastrointest Surg 2010;14:369-78.

8. Sandstrom P, Rosok BI, Sparrelid E, et al. ALPPS Improves Resectability Compared With Conventional Two-stage Hepatectomy in Patients With Advanced Colorectal Liver Metastasis: Results From a Scandinavian Multicenter Randomized Controlled Trial (LIGRO Trial). Ann Surg 2018;267:833-40.

9. Alvarez FA, Ardiles V, de Santibanes M, et al. Associating liver partition and portal vein ligation for staged hepatectomy offers high oncological feasibility with adequate patient safety: a prospective study at a single center. Ann Surg 2015;261:723-32.

10. D'Haese JG, Neumann J, Weniger M, et al. Should ALPPS be Used for Liver Resection in Intermediate-Stage HCC? Ann Surg Oncol 2016;23:1335-43.

11. Chan AC, Poon RT, Chan C, et al. Safety of ALPPS Procedure by the Anterior Approach for Hepatocellular Carcinoma. Ann Surg 2016;263:e14-6.

12. Balci D. Pushing the Envelope in Perihiler Cholangiocellularcarcinoma Surgery: TIPE-ALPPS. Ann Surg 2018;267:e21-2.

13. Petrowsky H, Gyori G, de Oliveira M, et al. Is partialALPPS safer than ALPPS? A single-center experience. Ann Surg 2015;261:e90-2.

14. Chan ACY, Chok K, Dai JWC, et al. Impact of split 
completeness on future liver remnant hypertrophy in associating liver partition and portal vein ligation for staged hepatectomy (ALPPS) in hepatocellular carcinoma:
Complete-ALPPS versus partial-ALPPS. Surgery 2017;161:357-64.

Cite this article as: Chan ACY, Lo CM. Associating liver partition and portal vein ligation for staged hepatectomy (ALPPS) - pushing the envelope in modulation of future liver remnant before major hepatectomy. Hepatobiliary Surg Nutr 2020;9(1):80-82. doi: 10.21037/hbsn.2019.10.28 